\title{
Intuition and Belief in Moral Motivation
}

\author{
Antti Kauppinen \\ For Gunnar Björnsson et al. (eds.), Motivational Internalism. Oxford University Press.
}

Final edit, December 2, 2013

It seems to many that moral opinions must make a difference to what we're motivated to do, at least in suitable conditions. To others, it seems that it is possible to have genuine moral opinions that make no motivational difference. Both sides - internalists and externalists about moral motivation - can tell persuasive stories of actual and hypothetical cases. Both sides can also offer a plausible deeper rationale for their picture of moral motivation. Internalists appeal to the distinctive practicality of morality, without which the practice of judging would seem to lack a point. Externalists emphasize the many belief-like features of moral judgment and the motivational inertness of belief, offering an explanation of practicality in terms of typical features of human nature. It is thus no wonder that the philosophical community has failed to reach a consensus on moral motivation.

Since both sides make a good case, it should be worth exploring the possibility that they are both in the right about something. My proposal for a kind of reconciliation begins by distinguishing between two kinds of psychological states with moral content. Call this Moral Thought Pluralism. According to it, there are, first, psychological states that may be labelled moral intuitions. They are spontaneous and compelling non-doxastic appearances of right or wrong that both attract assent and incline us to act or react. I argue that there is good reason to think that these intuitions, but not moral judgments, are constituted by emotional manifestations of moral sentiments. Second, there are moral judgments, which are ordinary 
beliefs about a moral subject matter. For the most part, I will use the terms 'judgment' and 'belief' interchangeably.

I argue that distinguishing moral intuitions and moral beliefs this way gives us an appropriately nuanced picture of moral motivation. Roughly speaking, my claim is that internalism is true about intuitions and externalism is true about beliefs or judgments. Moral intuitions, being constituted by emotions of a certain kind, are in themselves defeasibly motivating, and can move us to act even against our explicit beliefs. Moral beliefs, in turn, are associated with motivation in a number of different ways. Some beliefs non-accidentally coincide with motivation, since belief and motivation have a common cause in sentimental experience. Other beliefs motivate rational agents, because they implicitly attribute to an action a property that engages a rational agent's motivation. However, even if this kind of rationalist internalism is true of fully competent users of normative concepts, it need not hold for minimally competent moral thinkers. I thus leave open the possibility of having moral beliefs that do not tacitly amount to beliefs about some property that engages a rational agent's motivation. Such opaque moral beliefs will only motivate those who desire to do what is right de dicto. This means that a kind of externalism is true about moral judgments, and that morality is practical in many different ways. I label this view Disjunctivism About Moral Motivation.

Disjunctivism leaves conceptual room for many different kinds of amoralists, people who fail to be motivated in line with their judgments. But can it account for the reliable connection between beliefs and motivation in moralists - those who are not amoralists without artificial psychological redescription or making morality into a fetish? I argue that distinguishing between different external connections between belief and motivation helps defuse Michael Smith's well-known charges against externalism. There are three different ways in which changes in motivation can reliably track changes in judgment: as a result of 
common cause of belief and motivation in the case of intuition-driven change, as a result of rational disposition in the case of rationalizing moral beliefs, or as a result of a conscientious desire in the case of opaque moral belief. No theory-driven redescription is needed, and only the sort of de dicto desire based explanation that Smith himself considers is plausibly fetishistic (but externalists have no need to consider morally perfect agents as being so motivated).

In the final section, I note that the Moral Thought Pluralist account captures what is attractive about sentimentalist moral psychology without the need for any special moral semantics, since according to it, moral language expresses ordinary beliefs and only conversationally implicates the presence of motivation. Unlike some other forms of metaethical pluralism, it doesn't call for giving up the effort of finding universally applicable conceptual truths. Indeed, it provides not only an account of moral motivation, but also a plausible explanation of the persistence of the dispute between internalists and externalists.

\section{Two Types of Moral Thought}

When it comes to perception, the distinction between appearances and belief is widely accepted. It is most obvious in cases of known visual illusion, such as the Müller-Lyer is for most of us. Look at the two familiar lines in Figure 1.
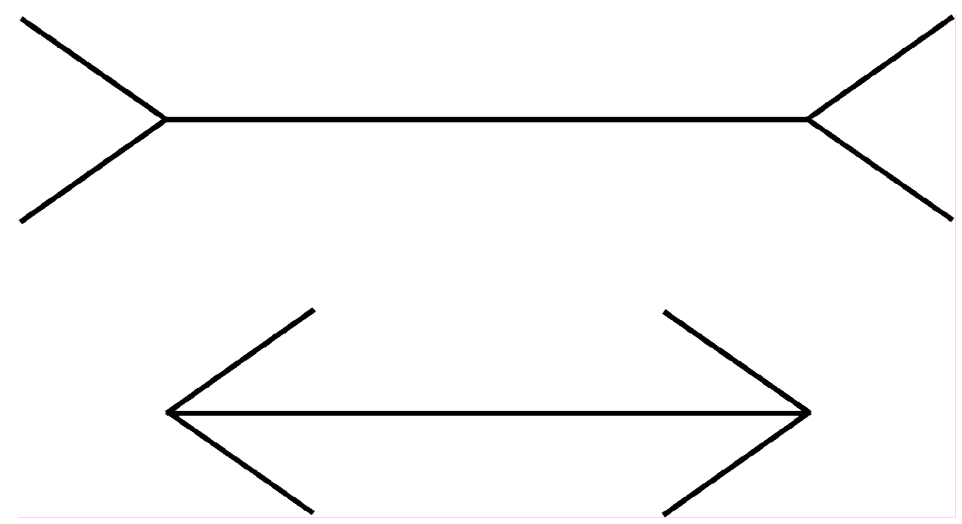
Figure 1. The Müller-Lyer illusion

Try as you might, unless you cover the heads or place a measure next to the lines, they will visually appear to be of different lengths. Yet you know they are not, so you don't believe so. You reject the appearance - it is, for you, a mere appearance. An appearance is thus not itself a belief - it is non-doxastic. Nor is it under direct voluntary control or the result of reasoning or inference from beliefs - in short, it's spontaneous. Yet the visual experience by itself attracts you to believe that the lines are of a different length. It seems to present to you the way things are independently of you. It is only because of other things you know that you don't take the appearance at face value. In short, it's compelling. Indeed, if you didn't know those other things, you'd arguably have perceptual justification for believing that the length is different (Pryor 2000).

An appearance or seeming is thus a non-doxastic, spontaneous, and compelling propositionally contentful state that shares the mind-to-world direction of fit with belief and putatively non-inferentially justifies belief. Many philosophers have recently argued that there are also quasi-perceptual appearances whose nature and epistemic role is importantly similar to perceptual appearances. ${ }^{1}$ Consider the proposition that if $\mathrm{S}$ knows that $p$, it's not an accident that $\mathrm{S}$ believes that $p$. If you merely think about it and reflect on it, perhaps imagining a Gettier-like case to clarify the content of the proposition to yourself, it will probably seem to you that the proposition is true. The truth of the proposition is compellingly presented to you in the experience, which attracts you to believe it. Such appearance isn't based on inference from what you believe or a theory you hold, so it can serve as a data point for competing theories to accommodate. Again like a perceptual

\footnotetext{
${ }^{1}$ See e.g. Bealer (1998), Bengson (2010), Chudnoff (2011a), Huemer (2005), Koksvik (2011), and Oddie (2005).
} 
appearance, a quasi-perceptual appearance can be misleading. For example, all the premises of a paradox seem true, even if one knows that at least one must be false (Sosa 2007).

These quasi-perceptual appearances plausibly correspond to what philosophers call intuitions. For example, to have the intuition that I couldn't have been born to different parents is to have a quasi-perceptual appearance to that effect. On this view, philosophically relevant intuitions are thus experiences of a particular kind: spontaneous and compelling non-doxastic presentations that result from merely thinking about propositions. Elijah Chudnoff (2011b) has recently persuasively argued that such intuitions can be sui generis while being constituted by other psychological states. These claims about philosophical intuitions are, of course, controversial, and I can't fully defend them here. I take it that the quasi-perceptual appearance view is plausible enough for me to stipulate that I'll use the term 'intuition' to refer to such seemings. It is worth noting that many other things that are often called 'intuitions' these days, such as beliefs based on gut reactions, or the outputs of what psychologists call System 1 (quick, nonconscious, associative, automatic, uncontrolled psychological processes), or people's responses to surveys, are therefore not intuitions in the sense I'll use, and I'll be making no claims concerning the role of such states in motivation. (Some such states, such as knee-jerk affective reactions, might be called pseudo-intuitions for their superficial similarity to genuine intuitions.)

Moral intuitions are in many ways like other intuitions. When we simply think about it, we 'just see' that it's wrong for a doctor to kidnap a healthy passer-by and kill him to use his organs to save the lives of five other people. Similarly, it appears on attentive consideration that there is a pro tanto moral reason for us to keep our end of a deal when the other side have done their part. These appearances are non-doxastic: a diehard utilitarian can have the intuition that one ought not secretly kidnap a healthy person to save five while believing the opposite, and without being irrational in the same way as someone who has 
contradictory beliefs. ${ }^{2}$ They are spontaneous in that they neither result from reasoning or inference from what we believe, nor are subject to direct voluntary control, once we focus on the propositions. They are compelling: the way things are, morally speaking, seems to be presented in the experience, and we're attracted to believe correspondingly.

Given the similarities to intuitions in general, it's not surprising that many take moral intuitions to be just the same kind of states as non-moral ones. ${ }^{3}$ Yet moral appearances have also distinctive features. The main differences are phenomenological and functional. When it strikes me that the two lines in Müller-Lyer are of a different length, or that a Gettierized subject doesn't know, it doesn't have any particular kind of phenomenological feel beyond the compelling character. This is one reason why Williamson (2007) and Sosa (2007) think that intuitions are simply dispositions to believe rather than experiences of any kind. But moral intuitions, once we clearly distinguish them from moral beliefs, at any rate characteristically have a rich and diverse phenomenology. Consider the proposition that it is wrong to indiscriminately bomb civilian targets in order to speed up the end of just war, even with the reasonable expectation that doing so also minimizes civilian casualties. As with the intuition that accidentally true justified beliefs are not knowledge, thinking about the proposition may require considering particular instances - fleshing out just what is involved by focusing, in this case, on the potentially wrong-making features.

So let's think about Hiroshima. Bearing in mind the reasoning that Truman took to justify the bombing, consider some of the effects of the thermal flash, blast wave, and the ensuing fire on people within several miles of the epicentre, as described by survivors:

\footnotetext{
${ }^{2}$ For the importance of different kinds of irrationality in seeing the non-doxastic character of intuitions, see Koksvik 2011.

${ }^{3}$ Classical intuitionists like Price, Sidgwick, Ross, and Audi (2004) take intuitions to be either dispositions to believe or just beliefs that result from mere understanding. This is similar to what Sosa (2007) says about intuitions in general. For Huemer's (2005) moral intuitions are sui generis quasi-perceptual appearances. This parallels what Bealer (1998), Bengson (2010), and Chudnoff (2011a) think about intuitions in general.
} 
A woman with her jaw missing and her tongue hanging out of her mouth was wandering around the area of Shinsho-machi in the heavy, black rain. (...) There were some who were burned black and died, and there were others with huge burns who died with their skins bursting, and some others who died all stuck full of broken glass. (...) I saw fire reservoirs filled to the brim with dead people who looked as though they had been boiled alive. (...) Men whose whole bodies were covered with blood, and women whose skin hung from them like a kimono, plunged shrieking into the river (...) I came onto I don't know how many, burned from the hips up; and where the skin had peeled, their flesh was wet and mushy. . . . And they had no faces! Their eyes, noses and mouths had been burned away, and it looked like their ears had melted off. It was hard to tell front from back. (quoted from Rhodes 1987, 721-6)

It's very hard, at least for me, to read these and further descriptions about the effects of the Hiroshima bombing without it appearing as morally wrong for me, and the arguments on the other side seeming shallow. In this case, the intuition is in line with the belief I held before, but it has a very different phenomenal character, and it increases my confidence in the prior belief. Arguably, in the experience the truth of the general proposition concerning indiscriminate bombing is also made manifest to me, especially when I consider other parallel cases. (This may be what Ross meant when he talked about 'intuitive induction'. ${ }^{4}$ )

The key functional difference from other intuitions is that moral intuitions appear to make a difference, directly, to how we act and react. Vivid intuitions can make a significant difference to what we do. This is most obvious when they go against what we believe. I believe the best interpretation of cases of so-called inverse akrasia is that things spontaneously morally appear to the agent one way in spite of their believing the contrary. In the metaethics literature, the most famous such example is Mark Twain's Huckleberry Finn, who believes that he ought to turn in the escaped slave Jim, with whom he's travelling down Mississippi, but can’t bring himself to do so. ${ }^{5}$ These contrary-to-belief appearances may not

\footnotetext{
${ }^{4}$ Here is what Ross says about intuitive induction: "[W]e see the prima facie rightness of an act which would be the fulfillment of a particular promise, and of another which would be the fulfillment of another promise, and when we have reached sufficient maturity to think in general terms, we apprehend prima facie rightness to belong to the nature of any fulfillment of promise. What comes first in time is the apprehension of the selfevident prima facie rightness of an individual act of a particular type" (Ross 1939, 170).

${ }^{5}$ Take the famous scene in which Huck is just about to give Jim up. He's paddling away toward some men hunting for escaped slaves, when Jim, thinking Huck's just checking out where they are, calls out “you's de bes'
} 
only exert pressure on existing beliefs, but directly move the agent to act against them.

Indeed, they may make a difference to the agent's actions even if the agent doesn't want them to. Further, different intuitions have different motivational effects. The intuition that what I've done is depraved might motivate me to hide, while the intuition that what I've done is unjust might motivate me to make amends. Since moral intuitions are intrinsically motivating, independently of the agent's beliefs and desires, they differ from ordinary intuitions, which make a difference to action only mediately. On this view, then, moral appearances differ from other quasi-perceptual appearances in having both a mind-to-world and a world-to-mind direction of fit (toward different contents). ${ }^{6}$

\section{Sentimentalism About Intuitions}

I've argued moral intuitions are non-doxastic, spontaneous, compelling, often phenomenologically rich, and often inherently motivational experiences. Though I can't consider alternative explanations here, I believe the best explanation of all these core features is that moral intuitions are experiences constituted by emotional manifestations of moral sentiments (see Kauppinen forthcoming a). ${ }^{7}$ A sentiment is a disposition to feel, act, and think in certain ways. Moral disapprobation toward $\phi$-ing, for example, is roughly a

fren' Jim's ever had; en you's de ONLY fren' ole Jim's got now ... Dah you goes, de ole true Huck; de on'y white genlman dat ever kep' his promise to ole Jim." What stops Huck from doing what he believes to be right when he hears Jim say such things, and lie instead? My money is on its just not seeming right to him.

${ }^{6}$ In this respect, moral appearances are thus like 'besires', though no belief is involved. Some might worry that there is no room in philosophy of mind for such bidirectional states that couldn't be at least counterfactually decomposed into more basic elements. (Michael Smith pressed this concern.) I respond to this in more detail elsewhere. The starting point is that the arguments for modal separability have much more force against judgment than intuition - it's easier to conceive of someone believing they ought to do something and wholly lacking motivation than to conceive of it appearing to someone they ought to do something while wholly lacking motivation. To use McDowellian terms, someone who lacks the motivational element doesn't share the conception of the situation with the agent who has the moral intuition, though she may have a belief with the same mind-to-world content.

${ }^{7}$ Graham Oddie (2005) argues in a similar vein that "experiences of value", to use his term for noninferentially justifying and motivating appearances, are desires. For him, "the desire that P is just the state of its seeming that P is good" (76). My problem with this suggestion is that it relies on an implausible view about the nature of desire - I don't believe that desires have the presentational character that emotions do. Certainly they don't present their objects as morally good. 
disposition to blame people for $\phi$-ing, to blame third parties who fail to blame those who $\phi$, and to blame oneself for $\phi$-ing, where blaming is constituted by negative emotions such as anger and guilt (cf. Blackburn 1998, Prinz 2007). I've argued elsewhere along classical sentimentalist lines that canonical moral sentiments are felt from what Hume called a common point of view - that is, as a result of occupying a perspective that could be shared by any reasonable person (Kauppinen 2010). I emphasize that this intuitive sentimentalism is not a claim about moral judgment, semantics, or metaphysics, but simply about one form of moral thought. As such, it is orthogonal to many metaethical disputes.

How does constitution by manifestations of moral sentiments account for the core features of moral appearances? To begin with, emotions plausibly constitute appearances. They present their target as having a property, sometimes called the formal object of the emotion: fear presents its target as dangerous. When it is a manifestation of a moral sentiment, anger presents its target as morally blameworthy. This presentational component of an emotion isn't a belief or judgment. Famously, one can fear getting on a plane while believing that it is perfectly safe. Someone who has this combination of emotion and belief may be irrational - the appearance involved in the emotion conflicts with the belief - but not in the same way as someone who holds contradictory beliefs. So emotional appearances are non-doxastic. My own view is that an emotion has its intentional content, and thus conditions of accuracy, in virtue of its very feel or phenomenal character (Kauppinen forthcoming a). Third, emotional appearances are also spontaneous - not necessarily in the sense that they arise quickly, but in that they are not under direct voluntary control, and that they are not the conclusions of inference. It may be that you can't help being awed by a rival when viewing her actions from the common point of view. It may, to be sure, take a lot of reflection to get in the position to feel something from the common point of view (which is another reason not to confuse moral intuitions with gut reactions). Fourth, emotional 
manifestations of moral sentiments, especially when felt from the common point of view, are compelling. It seems to us that the very wrongness or admirableness of an action is given to us in the experience, and we're attracted to believe correspondingly, even if it goes against our prior theory.

Finally, the rich and diverse phenomenology and motivational force of moral intuitions is readily accounted for if they consist in manifestations of moral sentiments. As Adam Smith emphasized, we should indeed talk about moral sentiments in the plural. Impartial resentment feels different and motivates differently from impersonally sympathetic suffering. The intuition that I've done something depraved might consist in self-directed contempt or disgust, while the intuition that I've behaved unjustly may be just resentment directed at myself.

So if moral intuitions are constituted by manifestations of moral sentiments, their core features and two directions of fit are readily explained. In a slogan, for something to seem wrong is for it to feel wrong. There are, of course, worries about intuitive sentimentalism as well. One obvious objection is that intuitions often taken to be intellectual quasi-perceptual appearances, not emotional ones. My response is that these quasiperceptual appearances are, in the relevant sense, intellectual: they result from merely thinking about the proposition, which may involve reflecting on what would be involved in its being true. They're not perceptual (I regard talk of a 'moral sense' as metaphorical), nor based on memory or introspection. It would be question-begging in favour of a priori intuitionism to restrict the relevant kind of thinking to mere understanding of the proposition. The second, related objection is that intuitions are supposed to play a justificatory role as well as an explanatory one. I argue elsewhere (Kauppinen forthcoming a) that sentimental appearances, in contrast to pseudo-intuitions like Jonathan Haidt's (2001) 'quick flashes of affect', do in fact defeasibly justify belief just as other quasi-perceptual or 
perceptual appearances do, and that sentiments felt from the common point of view avoid common defeaters.

The third common objection is that people can have intuitions without any distinctive phenomenological feel or motivational pull, for example when they consider a yet another trolley case. My response is that either the person has a what Hume called a 'calm passion' with a shallow phenomenology, and thus is after all in an emotional state that constitutes an intuition, or lacks an intuition but has an intuition-derived inclination to believe that I call an intuitive attraction. Suppose you resent using people as mere means. Sometimes when presented with a yet another trolley case that involves using someone as a mere means, the sentiment might manifest itself simply as an inclination to judge that the act is wrong. As long as this inclination is part of a pattern that does feature genuine emotions - in other cases of using someone as a mere means, you do or would get angry or feel guilt - it will still be the manifestation of a sentiment, and closely enough related to emotional intuitions to qualify as an intuitive attraction. So I conclude that there are two kinds of moral thought or opinion: straightforward beliefs and moral appearances or intuitions that are emotional manifestations of moral sentiments. ${ }^{8}$

\footnotetext{
${ }^{8}$ This view is not the only recent version of moral thought pluralism. According to Kriegel (2012), there are two types of moral judgment: some are what Tamar Gendler calls aliefs, while others are beliefs. On Kriegel's picture, aliefs are products of System 1, and contain a mix of cognitive, conative, and affective states, while beliefs are products of System 2. (Kriegel's account implies that there are no perceptual beliefs, since perception is a System 1 process!) Aliefs, but not beliefs, are intrinsically motivating; as he says, "both cognitivism and internalism are true of moral judgment, but in different senses" (Kriegel 2012, 481). That's the parallel with my view. On closer look, however, the accounts are vastly different. First, I don't believe in aliefs. Some alleged aliefs are just beliefs, others (non-judgmental) appearances, predictably accompanied by affective or motivational states. (Making the full case would require going through Gendler's examples.) Second, aliefs are significantly different from intuitions or appearances. They play no justificatory role, nor do they attract belief. Aliefs are not fit to play the same explanatory role as appearances. Consequently, Kriegel's account can't explain why beliefs tend to follow non-doxastic states (intuitions on my view, aliefs on his). Third, Kriegel's account has no place for connection between moral beliefs and motivation in rational agents, so aliefs are for him necessary for moral motivation. Thus, although Kriegel's aim is similar to mine insofar as he wants to explain the appeal of internalism and externalism by appealing to two distinct kinds of psychological state, there are several reasons to prefer my version of Moral Thought Pluralism.
} 


\section{Disjunctivism About Moral Motivation}

In the previous section, I defended a version of the thesis I call Moral Thought Pluralism. Here, I will explore the implications of Moral Thought Pluralism for moral motivation. Since the picture that emerges is that there are many separate paths to moral motivation, I'll call the view Disjunctivism About Moral Motivation, or Disjunctivism for short.

Let's assume the Humean theory of motivation is true, at least to the extent that beliefs alone don't motivate. This is a significant point in favour of externalism, since there is good reason to think that moral judgments are just beliefs about moral facts. After all, they behave just like beliefs with respect to evidence, degrees of certainty, and the like. ${ }^{9}$ Also, the language that we use to express moral judgments functions just like the language used to express beliefs. If we just accept that moral judgments are beliefs, we spare ourselves the need for any expressivist contortions. A belief, I take it, is a propositional attitude with a mind-to-world direction of fit that involves a commitment to its content being the case. The kind of commitment that distinguishes belief from seeming is best cashed out in terms of its role in reasoning. If you believe that $p$, you proceed as if $p$, treating $p$ as a premise in your reasoning. ${ }^{10}$ You believe rather than hope or suppose that a bridge is strong enough to carry you over when you plan on that being the case. You may refuse to plan on it being the case even if it seems to you that the bridge is strong enough, although the seeming will make the belief attractive.

But what about the practicality of morality? Many who are otherwise sympathetic to cognitivism find it hard to accept that it is an accident of human nature that we are generally motivated to avoid what we regard as morally wrong. But that seems to be what externalism entails, if moral motivation stems from a contingent desire to do what is right, which some

\footnotetext{
${ }^{9}$ See Smith 2002.

${ }^{10}$ For this type of approach to belief, see e.g. Brandom 1994.
} 
people have and others don't. So why is there a whiff of insincerity whenever someone says a behaviour is morally wrong and goes on to engage in it? Why does it seem to so many that it's not possible for a rational agent to remain entirely indifferent to her moral judgments?

On my view, this is explained by the fact that internalism is true of moral intuitions, and that moral beliefs are in several ways non-accidentally linked to motivation. I will begin with the relationship between moral intuitions and beliefs. As I've argued, moral intuitions defeasibly motivate, which is best accounted for by their being emotional manifestations of moral sentiments. Importantly, like other appearances, moral intuitions also attract us to assent to the corresponding proposition, to form the belief or judgment. Suppose I do form the belief that I ought to $\varphi$ on the basis of the intuition that I ought to $\varphi$. Since the intuition both defeasibly motivates me to $\varphi$ and attracts the belief that I ought to $\varphi$, my belief that I ought to $\varphi$ is non-accidentally linked to defeasible motivation to $\varphi$ - they have a common cause. Of course, on this view moral belief itself doesn't motivate. But it reliably co-occurs with motivation. It is nevertheless not pointless to form the belief, since it amounts to the kind of endorsement that makes a difference to further reasoning. If it merely appears to Huck Finn that slaves are worth respect, he may be motivated to treat them well, but will not assume the truth of the proposition in planning and theoretical reasoning.

This co-occurrence account comes tantalizingly close to some formulations of internalism. Here I am thinking in particular Jon Tresan's $(2006,2009)$ work defending what he calls de dicto or wide-scope internalism. The rough idea is that there is a difference between the wide-scope thesis that necessarily, if $\mathrm{S}$ judges that she morally ought to $\varphi$, she is at least somewhat motivated to $\varphi$, at least in $\mathrm{C}$, and the narrow-scope thesis that if $\mathrm{S}$ judges that she morally ought to $\varphi$, she necessarily is at least somewhat motivated to $\varphi$, at least in C. In the latter case, the judgment, the psychological state itself, constitutes or necessitates motivation, while in the former the concept of moral belief applies only to agents who are 
motivated, or appropriately linked to motivated agents. The wide-scope view leaves it open that some other state co-occurring with belief provides the motivation. Similar suggestions have been made in recent Hume scholarship. Elizabeth Radcliffe argues that what Michael Smith's calls ‘the Moral Problem' - reconciling internalism, cognitivism, and the inertness of belief - can be solved if we distinguish between the sentiments that cause moral belief and moral belief itself. As in my picture, it is the sentiments rather than beliefs that motivate, but the presence of motivation with belief is guaranteed, because "a belief about morality only counts as a moral judgment if it is based on the proper experienced sentiment" (Radcliffe 2006, 362).

Radcliffe's version of the wide-scope internalist view is evidently closely parallel to mine. However, its internalist aspect goes too far. There isn't sufficient reason to deny that we can form genuine moral beliefs on other basis than sentiment. For example, we can surely reason our way into them from other moral beliefs or accept somebody's moral testimony without it triggering a sentimental intuition. The co-occurrence of beliefs and motivating intuitions remains contingent. ${ }^{11}$

\section{How Beliefs Motivate}

I do think, however, that something very close to internalism is true about some moral beliefs. More precisely, I think that it's almost true that someone who thinks that she ought to $\varphi$ necessarily has some motivation to $\varphi$ if she is practically rational. But that's true only insofar as in having a moral belief, the subject attributes to something a property that engages the motivation of any rational agent. This turns on at least two things: what the content of moral ought beliefs (and normative beliefs in general) is, and what (if any)

\footnotetext{
${ }^{11}$ It's less clear how this affects Tresan's account, since it's less clear how he conceives of the beliefindependent sources of motivation. What I say in this paper leaves it open for a community-wide wide-scope internalist to argue that there can be no genuine moral beliefs, unless at least some members of the community have intuitions and thus are motivated in line their beliefs.
} 
contents are such that they necessarily engage any rational agent's motivation. In fact, I think that a third feature also makes a difference: just how good the subject's grasp of the relevant concepts is. I'll argue that subjects who are only minimally competent may have genuine moral beliefs without being rationally required to be motivated accordingly.

To see why this is so, let's begin with the cognitivist truism that a moral judgment is a belief that something has a moral property. It differs from other beliefs only in its content: it represents its object as having a moral property. But what is it to attribute a moral property to something? One tempting way to answer this question is to begin with a metaphysical analysis of moral properties. Suppose that moral rationalists are correct, so that if S morally ought to $\varphi, S$ has most reason to $\varphi$ (perhaps on certain kind of grounds that are distinctive of morality). Does it follow that when $\mathrm{S}$ believes she morally ought to $\varphi$, she thereby believes she has most reason to $\varphi$ ? No. Property identity does not suffice for identity of cognitive role, as the standard case of water and $\mathrm{H}_{2} \mathrm{O}$ shows. Just as you can believe that something is water without believing that it is $\mathrm{H}_{2} \mathrm{O}$, you can believe you morally ought to $\varphi$ without believing you have most reason to $\varphi$, even if that happens to be true. Hence, even if metaphysical rationalism is true, and even if practical rationality requires being motivated to do what you believe yourself to have most reason to do, it does not yet follow that practical rationality requires you to be motivated by what you think you ought to do.

This type of argument has recently been made by Mark van Roojen (2010) in defence of the possibility of (individual) rational amoralism. As he puts it,

If rationalism is correct, a rational person can have a thought that something is right and yet remain unmoved, but only provided that she is not in a position to recognize the identity of rightness with the property of being rationally required. If she does or should recognize the identity then she also should rationally be motivated. (van Roojen 2010, 516-7) 
To be sure, those who reject rational amoralism, such as Michael Smith, have a response open to them. Smith (1994) believes that for something to be what someone ought to do is for it to be the case that the subject's fully informed and maximally coherent counterpart her ideal advisor - would want her to want to do it. Now, in the case of water and $\mathrm{H}_{2} \mathrm{O}$, the property identity is famously a posteriori: it takes empirical investigation of the watery stuff around us to establish that water is necessarily $\mathrm{H}_{2} \mathrm{O}$. But, Smith might respond to van Roojen, the identity of being the thing to do and being what one's ideal advisor would want one to want to do is a priori. It is an unobvious conceptual truth that is implicit in "the various inferential and quasi-inferential roles that such judgments have" (Smith 1997, 103). That is, when we look at the discriminations and inferences that competent users of moral (and more broadly normative) concepts are disposed to make, we can see that they form a pattern that is best explained by implicit belief in an ideal advisor's desires. So Smith can say either that everyone capable of thinking moral thoughts does in fact recognize that being the thing to do is being what one's ideal advisor would want one to want to do, or, more weakly, that every competent moral thinker is in a position to recognize the identity. Smith further argues that coherence requires one to desire as one believes one's ideal advisor would want one to desire, so that any agent who is rational in the narrow sense of having a disposition for coherence will desire to do what she believes she ought. If Smith's claims about content and rational motivation are true, then on both strong and weak readings of the implicit content of ought thoughts, moral thinkers are rationally required to be motivated by ought-thoughts - by van Roojen's own lights.

I do not, as a matter of fact, believe that normative claims have the content that Smith attributes to them. I think that instead of being beliefs about an ideal advisor's desires, they are beliefs about fittingness of attitudes, which in turn are implicitly beliefs about the attitudes of ideal subjects of various kinds (Kauppinen forthcoming b). And in work in 
progress, I offer a different explanation of why practical rationality requires desiring to act in ways one believes to be fittingly approved of or demanded from a moral point of view. But these differences matter less than the commonalities between Smith's view and mine. We both believe that fully competent subjects who have moral ought thoughts at least implicitly have thoughts with a content that rationalizes motivation.

So does it follow that practically rational agents are motivated in line with their moral beliefs? I don't think so. The issue turns on the relative transparency or opacity of rationalizing content. Smith assumes (and I agree) that the contents of beliefs are at least in part fixed by the inferential dispositions of the believer. Importantly, one may possess concept-relevant inferential dispositions to greater or smaller extent. For example, we can attribute sphericality-beliefs to someone who is disposed to draw only a few of the consequences of something being spherical. Among such dispositions may also be dispositions to defer to others in establishing the referent, as van Roojen (2010) emphasises in his argument. Consequently, people may possess a concept to only to a small degree, and do so parasitically on others who possess it to a higher degree - not every competent moral thinker is equally competent. I'll say that someone who has such a precarious grasp of a concept is only capable of opaque beliefs featuring it. It's not clear to her what she commits herself to in forming the belief. This is not itself irrational - for example, it is not irrational for me to think of some things that they are spherical, in spite of being disposed to draw only a few of the consequences of being spherical. It is a consequence of this picture of content that it may be possible for someone to have moral beliefs in spite of lacking the inferential and discriminatory dispositions that would license attributing belief in ideal advisors or subjects. For example, they may not be properly sensitive to demands of coherence in their desires. As long as their dispositions are close enough to those of fully competent moral thinkers, we can still attribute moral beliefs to them. But as long as such opaque moral 
beliefs do not implicitly refer to the attitudes of ideal advisors or subjects, the subjects need not be irrational if they fail to be motivated in accordance with their beliefs.

The upshot of this last point is that we should only accept the borderline externalist thesis that I'll label Transparent Moral Belief Rationalism. According to it, any agent is necessarily either motivated to act in accordance with her transparent moral beliefs - moral beliefs that involve solidly grasped normative content - or is practically irrational. Since this thesis attributes rationally required motivation only to a subset of moral beliefs, or perhaps believers, it is not internalist. To put the point slightly differently, even if Smith is right about the contents of the beliefs of fully competent users of normative concepts, he is wrong about the contents of the beliefs of minimally competent users of normative concepts. And minimally competent users of concepts can still form genuine moral beliefs. Transparent Moral Belief Rationalism is thus compatible with Opaque Moral Belief Anti-Rationalism.

If we are motivated in accordance with opaque moral beliefs, it will not be the result of the belief itself or the belief together with a disposition toward rationality. It may be because we're conscientious, desiring to do whatever is right, or desiring to have a nonderivative desire for whatever is right. But neither conscientious desire nor practical rationality is necessary for moral motivation: both opaque and transparent moral beliefs may be the result of a moral intuition, which will provide corresponding motivation. Indeed, there may be a kind of feedback loop: an occurrent belief might trigger the original intuition by association, and the intuition then provide a motivation act in accordance with the inert belief. ${ }^{12}$ We get an even more complex - and in my view more realistic - picture, when we take into account the possibility that belief-based motivation of either transparent or opaque kind strengthens or clashes with intuition-based motivation. (For example, Huck Finn's desire to do the right thing might conflict with the intuition pulling in the other direction.)

\footnotetext{
${ }^{12}$ This is in line with some suggestions in Railton (2009).
} 


\section{Amoralists}

As I said at the outset, many of us have the modal intuition that it is possible for someone to make a genuine moral judgment without having any relevant motivation - that is, amoralism is possible. The Disjunctivist account leaves room for different kinds of amoralist. Someone who has transparent moral beliefs and thus stands under a rational requirement to be guided by them may nevertheless be practically irrational and fail to be motivated. But there are also rational amoralists - those who have opaque moral beliefs and lack both the rationally optional conscientious desire and moral intuition. There could be any number of explanations for why a rational amoralist lacks a conscientious desire - listlessness, cynicism, and so on - and I have nothing to add to the existing stories. But thinking about the role of intuitions might help make further distinctions among the amoralists. It is probably true that some people are simply unable to have moral intuitions. Psychopaths might be a case in point, perhaps because of lacking empathy, which may be necessary to adopt the common point of view. ${ }^{13}$ Nothing in my view calls into question the ability of psychopaths to form genuine moral beliefs, though they may have to defer to the testimony of others to acquire justification or even secure reference. The listless and even the cynics, however, might be only fleeting amoralists, even if their desires remain dead or hostile to morality. Moral intuitions, after all, are fundamentally non-voluntary. They might pop up all of a sudden to get even a cynic to perform a random act of kindness.

\section{The Fetishism Argument}

\footnotetext{
${ }^{13}$ An anonymous referee pressed the following sort of worry: couldn't it seem to a psychopath that murder is more seriously wrong than lying, even if she lacks all moral sentiments? My response is that such a seeming, which could plausibly exist, wouldn't amount to a moral intuition. Rather, it would be something like a social intuition, a sense that moralists would disapprove of one more than of the other. It might consist in some other kind of feeling. (Note that lacking all moral sentiments is probably very rare, even among psychopaths.)
} 
I've argued that externalism is true about moral judgments, which are only contingently, though non-accidentally, linked to motivation. Any kind of externalism faces an important challenge, Michael Smith's $(1994,1996)$ justly famous Fetishism Argument. In this section, I'm going to argue that the Disjunctivist model captures modal intuitions about change in moral motivation and moral perfection well.

I will begin with a recap of the Smith's Argument. In what is perhaps the most careful formulation, Smith (1996) first defines a 'moralist' as anyone who is not an amoralist. Where an amoralist is motivationally indifferent to her judgments, a moralist is reliably motivated to $\varphi$ if she judges she ought to $\varphi$, as long as she is practically rational. (For the rest of this section, I'll take being practically rational as read, unless mentioned otherwise.) Internalists, of course, think that anyone who makes moral judgments is necessarily a moralist, while externalists believe that's a contingent matter. But, Smith notes, both will agree that it is a conceptual truth that if someone is a moralist and makes a moral judgment, she will be motivated accordingly. The debate then turns on which side can offer a better explanation of this conceptual truth, which Smith labels Weak Moralist Internalism. For internalists, it is simply a consequence of the conceptual truth that anyone who makes a moral judgment will be motivated accordingly, unless practically irrational. If I judge that I ought to maximize happiness, I will be directly, non-instrumentally motivated to maximize happiness. For externalists, in contrast, Weak Moralist Internalism is explained in part by the nature of moral judgment and in part by the nature of moralists, as opposed to amoralists. But what is the difference between moralists and amoralists? According to Smith, externalists can only say that "what makes someone a moralist, as opposed to an amoralist, is the fact that she contingently desires to do what is right." (Smith 1996, 180) This 
conscientious desire, together with a belief that it is right to $\varphi$ in $\mathrm{C}$, explains the externalist moralist's desire to $\varphi$ in $\mathrm{C}$ (when rational), and thus the truth of Weak Moralist Internalism.

This type of externalist account features what I'll call a Type I conscientious moralist. Smith issues two different challenges to it. (I emphasize this, because they are not always kept apart in the literature.) The first concerns explaining motivational change. If a moralist changes her mind about what is fundamentally right, her motivation, by definition, changes accordingly. But why? Here's Smith's case. A graduate school friend of his

believed that it is always right to maximize happiness and minimize suffering, and fundamentally so ... Over the years, however, via a process of argument, he came to change his mind. He now believes that it is sometimes right to give extra benefits to his family and friends, even when doing so cannot be given a utilitarian justification. He is also a moralist. His moral motivations have followed reliably in the wake of his new judgement, at least absent weakness of will. (Smith 1996, 180)

According to Smith, the natural psychological description of what happened is that the friend first non-instrumentally wanted to maximize happiness, and then, "as a result of changing his moral beliefs" (ibid.), non-instrumentally wanted to give extra benefits to the near and the dear. This is just how a constitutional internalist sees it, since judgment that one ought to $\varphi$ constitutes or, together with a disposition toward rationality, causes motivation to $\varphi$. The externalist, in contrast, must appeal to a Type I conscientious desire to do whatever is right in addition to the judgment itself. Combined with the belief that maximixing happiness is right, the conscientious desire gives rise to a derivative desire to maximize happiness. Once the rightness belief changes, the conscientious desire gives rise to a derivative desire to give extra benefits to the near and the dear. This, for Smith, is a "manifestly false and theorydriven redescription" of psychological change. (Notice that there's so far no talk about fetishism.)

Smith's second criticism is that externalism involves a "quite incredible picture of moral perfection" (Smith 1996, 181). For the internalist, a morally perfect agent is someone 
who knows what to do and is consequently motivated to do it for its own sake. For the externalist, by contrast, a morally perfect agent is someone who knows what is right and desires to do whatever she thinks is right. If what is in fact right is respecting rational agency, a morally perfect Type I conscientious externalist agent knows that respecting rational agency is morally right, has a non-instrumental desire to do whatever is morally right, and an instrumental desire to respect rational agency. This picture, according to Smith, is a serious distortion of what moral perfection involves. Agents who only instrumentally care about what is right ( $d e$ re) "seem precious, overly concerned with the moral standing of their acts when they should instead be concerned with the features in virtue of which their acts have the moral standing that they have." (Smith 1996, 183) Such agents are not, in fact, morally perfect, but rather make doing the right thing into a kind of fetish.

\section{Three Kinds of Moralist}

I've given a fairly detailed account of the Fetishism Argument, since I believe it is often somewhat misconstrued in the literature. There are two points I want to emphasize. First, the intuitive datum is only the wide scope one: necessarily, if a moralist's judgment changes, her motivation changes accordingly. It isn't the narrow-scope one that change of judgment itself constitutes or causes motivation (in rational agents); that would be begging the question in favour of constitutional internalism. Second, there are indeed two challenges: avoiding both theory-driven redescription of psychological change and a fetishistic account of moral perfection. A satisfactory account of moral motivation must be address both simultaneously.

I do not have the space to properly discuss existing responses to Smith's argument, but it seems to me they fail on at least one of the counts. The responses divide into two classes. Some argue that Type I conscientious desires aren't fetishistic, and others defend an 
alternative to the Type I conscientious moralist. ${ }^{14}$ The first line seems unpromising to me while it is easy to show that the desire to do whatever is right isn't always fetishistic, that's not sufficient to explain reliable motivational change across the board. The second line of response makes use of the wide scope of the intuitive datum. A number of explanations that appeal to other desires than the desire to do whatever is right have been proposed. For my money, the most promising of these appeal to a second-order desire to acquire a nonderivative ('de re') desire to do whatever is right (de dicto) (Copp 1997, Dreier 2000). Only such desires have the requisite generality to account for all kinds of motivational change. ${ }^{15}$ I'll call people with such motivation Type II conscientious moralists. Since Type II conscientious moralists reliably have non-derivative desires to promote happiness or, after change of judgment, privilege family, the account is not obviously subject to the fetishism charge. But, it seems to me, this account is subject to Smith's first charge of merely theorydriven psychological redescription. It is highly implausible that all moralists have such involved second-order desires. Would anyone describe Smith's grad school friend's psychology, for example, in those terms without a theoretical stake?

So it's worth looking at a different response that falls straightforwardly out of the Disjunctivist account I've been developing. The account allows for two kinds of amoralist: the first kind has transparent moral beliefs but is irrational, the second has opaque moral beliefs and lacks (in a given case) both moral intuition and conscientious desire. If moralists are the contrast class, it follows that moralists come in three varieties: rational transparent moralists, who are at least implicitly aware of the rational authority of moral thoughts and have a disposition to be rational, intuitive moralists who (at least) have motivating intuitions, and conscientious moralists (of whatever type) who have some kind of desire to do whatever

\footnotetext{
${ }^{14}$ Many combine both (e.g. Olson 2002).

${ }^{15}$ It seems to me that accounts that appeal to desires for particular kinds of good things founder on this point (e.g. Strandberg 2008, Tenenbaum 2013).
} 
is right. (Most of us probably switch from one class to the other, but I don't think that matters.) For the first kind of moralist, the explanation of moral motivation is essentially the same as Smith's, so there is no dispute on that score. The interesting question is whether intuitive and conscientious moralists meet Smith's challenges.

Start with the intuitive moralist account. Suppose that reading Peter Singer made it seem to Smith's grad school friend, call him Philip, that morality demands impersonal utility maximization, so he both judged accordingly and formed a non-instrumental desire to maximize utility impersonally. (I'm going to assume for simplicity that he doesn't suffer from weakness of the will or the like.) Then, "via a process of argument", Philip was brought to change his mind. It's good to reflect on what kind of argument might have been at issue here. Smith doesn't tell us, but the most likely candidate is either appeal to intuitions about particular cases, or appeal to Rossian intuitions about pro tanto principles. That's how people are generally argued out of utilitarianism. Some such process leads an intuitive moralist to change her sentiments about utility maximization. The change of sentiment, again, brings in its wake both change of judgment and change of motivation. Now Philip judges it right to privilege the well-being of family and friends and non-derivatively desires so. I don't think there's any reason to think this explanation of motivational change is any more theoretically motivated than the internalist's, when the case is filled in this way. The intuitive moralist's motivations and judgments both reliably follow her intuitions, so her motivation reliably changes when her judgments do.

The conscientious moralist, in turn, judges without intuition. In her case, motivation really does result from combining belief about duty with desire to do whatever one's duty is. Let's say that a purely conscientious moralist is someone who has only opaque moral beliefs without ever having intuitions. Such a person might be an autist who is unable to take the 
perspective of others, and therefore unable to adopt the common point of view. ${ }^{16}$ Why would such a person, call him Frank, change his fundamental moral beliefs? Such change is unlikely to be driven by reasoning from other beliefs - after all, we're talking about fundamental change, like that from pure utilitarianism to agent-relative consequentialism so the most likely source is testimony. Let's say that as a result of recognizing his emotional limitations, Frank is unsure about first-order moral matters, but considers Michael a veritable guru. As far as he's concerned, if Michael believes that $p, p$ is the case. As before, Frank starts out as a utilitarian. But now Michael tells him that utilitarianism is false and that it is morally right to prioritize the near and the dear. It doesn't seem either way to Frank, but as he holds Michael in high regard, he forms the belief that it is morally right to prioritize the near and the dear. Being conscientious, he forms the instrumental desire to act in ways that benefit friends and family. Now, when the psychological background is filled in this way, I don't think that appealing to a conscientious desire is a "manifestly false and theory-driven redescription" of someone like Frank's motivational change. Since he's oblivious to the rationality of morality's demands, so that his rational dispositions aren't engaged by the change of judgment, what else would explain why someone like him comes to be motivated accordingly?

What about the fetishism charge? Smith introduces the issue by saying "ask yourself where someone who is morally perfect fits into the externalists' picture of the divisions among agents". On my judgment externalist picture, again, there are four kinds of agents: amoralists, rational transparent moralists, intuitive moralists, and conscientious moralists. I think the most plausible answer is that the morally perfect are either rational transparent moralists (which gives us Smith's answer) or intuitive moralists. The latter feel negatively

\footnotetext{
${ }^{16}$ Not all autists are unable to take the perspective of others. Temple Grandin, whom Jeannette Kennett (2002) uses as a putative counterexample to sentimentalist accounts, seems to have such ability, required for conscious deception, for example. See Kauppinen (2010) for more.
} 
toward things that are genuinely wrong and positively toward things that really are morally right or obligatory, and their judgments are based on these sentiments, so they base their practical and theoretical reasoning on moral truths. And of course, given this, they noninstrumentally desire to do just the things they ought to do. For example, a morally perfect person has a negative sentiment toward failing to serve the well-being of her family and friends, and is motivated to serve the well-being of her family and friends. We can, if we like, describe this as her being moved by the well-being of her family and friends. It certainly isn't the case that she is moved by the rightness of serving the well-being of her family and friends. So there's no grounds for saying that a purely intuitive moralist is fetishistic, even though her motivation isn't provided directly by the judgment.

Once externalists distinguish among moralists this way, they can even grant that there is something defective about the purely conscientious moralist. By force of circumstance, she will only be motivated to do the right thing in a roundabout way, at least initially - of course, as others have pointed out, nothing rules out a conscientious moralist coming to have an intrinsic concern for what she regards obligatory (and if she is Type II, she will desire coming to have such concern). But that only means that not every moralist is equally perfect, which is a welcome result.

\section{Conclusion: Varieties of Sentimentalism and Pluralism}

I've argued that we can best understand the phenomena of moral motivation in terms of a Disjunctivist account, according to which internalism is true about intuitions, and beliefs are associated with motivation in a variety of ways. In this final section, I will briefly compare the Disjunctivist account with related views about moral motivation, and lay out some of its advantages. 
There are, of course, many views for which emotions and attitudes play a key role in motivation. What non-cognitivist and hybrid expressivists like Gibbard (1990), Blackburn (1998), and Ridge (2005), on the one hand, and emotionist cognitivists like Prinz (2007) have in common is that they believe moral judgments are at least in part sentimental. As I've said, I reject this view, in part because it has trouble making sense of other psychological features of moral judgments and in part because it can't account for moral semantics. I believe that as far as moral psychology goes, the attraction of such views can be fully captured by taking moral intuitions to be sentimental. With this proviso, the view I've defended has many commonalities with Prinz's (2007) account of moral judgment. We both emphasize that moral emotions can be representational and that they come in different varieties. For the naturalistically minded, I believe that the multifarious empirical evidence that Prinz presents in favour of his view can be equally well captured by intuitive sentimentalism.

The Disjunctivist view I've defended isn't the only kind of pluralistic account of moral motivation. The existing accounts are pluralist either about judgments or about concepts. Judgment pluralism comes in two varieties (both appear to be endorsed in Gill 2009). Content pluralism says that moral judgments with certain kind of content intrinsically motivate, while judgments with different content don't. I think my view can accommodate the evidence for this account quite nicely. It is simply more likely that we have sentimental intuitions about or metaphysical insight into certain subject matters, so that judgments about them are characteristically associated with motivation. Agent pluralism says that some agents are intrinsically motivated by their judgments, while others aren't. Both nevertheless genuinely make moral judgments (but why?). The evidence for this view is thin, but the Disjunctivist account at least accommodates the scenario. After all, it allows for different types of moralists and amoralists. 
Finally, Ragnar Francén (2010) has defended conceptual pluralism about moral motivation, according to which different people have different concepts of moral judgment (or opinion) - some people have an internalist concept, others an externalist one. Hence, there is no single conceptual truth about moral motivation. Francén's motivation for this view is that people who are by ordinary lights competent with moral concepts persistently have different intuitions about the crucial cases, such as amoralists. Given that they're willing to apply concepts differently, there's a prima facie case to be made that these people simply have different concepts, which each of them deploys correctly. The alternatives are that some are making mistakes applying the shared concept, there's some type of indeterminacy in the shared concept, or that the parties don't really disagree but talk past each other. I have no space here for a full response to this interesting challenge, but the Disjunctivist account supports an analysis of the interminable debate as a case of talking (or perhaps thinking) past each other. People who focus on moral intuitions - which are after all the most striking kind of moral thought - or metaphysically transparent beliefs will predictably have internalist (conceptual) intuitions. People who focus on non-intuitive, nontransparent beliefs will predictably (and correctly) have externalist intuitions. Since the different kinds of moral thoughts haven't been clearly enough distinguished in the literature, it is not surprising that even very competent speakers fail to heed the subtle distinctions. My hope is that this paper will make a small contribution to disentangling the issues.

\section{References}

Audi, Robert. 2004. The Good in the Right. Princeton, NJ: Princeton University Press. 
Bealer, George. 1998. "Intuitions and the Autonomy of Philosophy." In Rethinking Intuition: The Psychology of Intuition and Its Role in Philosophical Inquiry, edited by Michael DePaul and William Ramsey, 201-39. Lanham, MD: Rowman \& Littlefield.

Bengson, John. 2010. The Intellectual Given. Dissertation, University of Texas at Austin. Blackburn, Simon. 1998. Ruling Passions. Oxford: Clarendon Press.

Brandom, Robert. 1994. Making It Explicit. Cambridge, MA: Harvard University Press.

Chudnoff, Elias. 2011a. "The Nature of Intuitive Justification.” Philosophical Studies 153: $313-33$.

Chudnoff, Elias. 2011b. "What Intuitions Are Like.” Philosophy and Phenomenological Research 82 (3): 625-54.

Copp, David. 1997. "Belief, Reason, and Motivation: Michael Smith's The Moral Problem." Ethics 108 (1): 33-54.

Dreier, James. 1990. “Internalism and Speaker Relativism.” Ethics 101 (1): 6-26.

Francén, Ragnar. 2010. “Moral Motivation Pluralism.” Journal of Ethics 14 (2): 117-48.

Gill, Michael. 2009. "Indeterminacy and Variability in Metaethics.” Philosophical Studies 145 (2): 215-34.

Huemer, Michael. 2005. Ethical Intuitionism. New York: Palgrave MacMillan.

Kauppinen, Antti. 2010. "What Makes a Sentiment Moral?” Oxford Studies in Metaethics 5: $225-56$.

Kauppinen, Antti. Forthcoming a. "A Humean Theory of Moral Intuition.” Canadian Journal of Philosophy.

Kauppinen, Antti. Forthcoming b. "Fittingness and Idealization." Ethics.

Kennett, Jeanette. 2002. “Autism, Empathy, and Moral Agency.” Philosophical Quarterly 52: $340-57$. 
Kriegel, Uriah. 2012. "Moral Motivation, Moral Phenomenology, and the Alief/Belief

Distinction." Australasian Journal of Philosophy 90 (3): 469-86.

Koksvik, Ole. 2011. Intuition. PhD Dissertation, Australian National University.

Oddie, Graham. 2005. Value, Reality, and Desire. Oxford: Oxford University Press.

Olson, Jonas. 2002. “Are Desires De Dicto Fetishistic?” Inquiry 45 (1): 89-96.

Pryor, James. 2000. “The Skeptic and the Dogmatist.” Noûs 34 (4): 517-49.

Prinz, Jesse. 2007. The Emotional Construction of Morals. Oxford: Oxford University Press.

Radcliffe, Elizabeth. 2006. "Moral Internalism and Moral Cognitivism in Hume’s Metaethics." Synthese 152 (3): 353-70.

Railton, Peter. 2009. “Internalism for Externalists.” Philosophical Issues 19: 166-81.

Ridge, Michael. 2006. "Ecumenical Expressivism: The Best of Both Worlds?" Oxford Studies in Metaethics 2: 302-36.

van Roojen, Mark 2010. “Moral Rationalism and Rational Amoralism.” Ethics 120 (3): 495525.

Ross, W.D. 1939. Foundations of Ethics. Oxford: Oxford University Press.

Smith, Michael. 1994. The Moral Problem. Oxford: Blackwell.

Smith, Michael. 1996. “The Argument for Internalism: Reply to Miller.” Analysis 56 (3): $175-84$.

Smith, Michael. 2002. "Evaluation, Uncertainty and Motivation.” Ethical Theory and Moral Practice 5: 305-20.

Sosa, Ernest. 2007. A Virtue Epistemology: Apt Belief and Reflective Knowledge. New York: Oxford University Press.

Strandberg, Caj. 2007. "Externalism and the Content of Moral Motivation." Philosophia 35: $249-60$. 
Tenenbaum, Sergio. 2013. "Externalism, Motivation, and Moral Knowledge.” In Ethical Naturalism: Current Debates, edited by Susana Nuccetelli and Gary Seay, 211-25. Cambridge: Cambridge University Press.

Tresan, Jon. 2006. “De Dicto Internalist Cognitivism.” Nô̂s 40 (1): 143-65.

Tresan, Jon. 2009. "Metaethical Internalism: Another Neglected Distinction.” Journal of Ethics 13 (1): 51-72.

Williamson, Timothy. 2007. The Philosophy of Philosophy. Oxford: Oxford University Press. 